\title{
Comparative Study of Governance Information Systems for Scientific Research
}

\author{
Khaoula Benmoussa ${ }^{1}$, Majida Laaziri ${ }^{1}$, Samira Khoulji ${ }^{1}$ and Kerkeb Mohamed Larbi ${ }^{2}$ \\ 1,2Information System Engineering Resarch Group \\ ${ }^{1}$ National School of Applied Sciences of Tetouan. \\ ${ }^{2}$ Faculty of Sciences of Tetouan. \\ Abdelmalek Essaâdi University \\ Benmoussakhaoula24@gmail.com, majida.laaziri@gmail.com, khouljisamira@gmail.com, \\ kerkebml@gmail.com
}

\begin{abstract}
The research and innovation effort is a major asset in international economic competition. Research and technological development are key areas to achieve this, contributing to economic growth and job creation. In order to achieve the objective of becoming the most competitive and dynamic knowledgebased economy in the world, several government have developed in recent years information systems to manage their scientific research.

As part of the development of instruments to support the strategic management of research at an institution, in particular a university, the design of an information system that meets the requirements of a high level of operational, tactical and strategic institutional authorities seems paramount. International models of research governance or simply the remarks of faculty-researchers at universities help to build a performance management information system.

In this article we will present a comparative study between the information systems of scientific research, in particular the Chile Research Management System (SGI) and the Argentine Science and Technology Information System (SICYTAR), Scientific Information System of Andalusia Spain (SICA), GRAAL of France (management of research data, application of laboratory activities) and others.
\end{abstract}

\section{Introduction}

The governance of scientific research reveals the roles of different actors in the research system, how the rules of the organization of the system work, how decisions are taken and how changes in the overall research system come into being

This international comparative study on the governance of innovation was launchedin order to see whether North African countries could learn from governance practices in other countries. North African universities are particularly interested inresearch governance as key actors are rethinking how the research governance system could be improved to make research policy more effective. 
The improvement of a scientific research information system on its functionalities, structure, strategies and techniques, etc. requires a comparative study of the existing research information systems and needs also to take into account the remarks of academic researchers at universities.

This paper is based on a comparative study in six countries: France, Spain, Italy, Argentina, Chileand Morocco. The objective of the studyis to describe national models of public governance and examples of good practice.

\section{Research Management System (SGI), Chile}

Since 2001, the decision to transform the University of Talca into a complex university was adopted, which made it actively involved in the development of research and graduate programs. This decision results in higher academic productivity, particularly in research. Since then, a steady increase has been observed in the number of projects spent in various competitive funds, the number of indexed publications, and enrollment in graduate programs.

The University of Talca has developed the Research Management System (SGI) to support the academic activities of their researchers. The incorporation of SGI at the University of Talca has contributed to a significant increase in the number of active researchers and the number of research projects carried out, the number of publications and the allocation of external and internal funds.

Initially, the system was structured to include a range of information services for the exclusive use of specific users according to their profile, researchers, visitors and others in terms of programs, projects, events and products resulting from the research activities developed. The strategic level of the system aims to have a set of indicators and related statistics of available research capabilities[1-3].

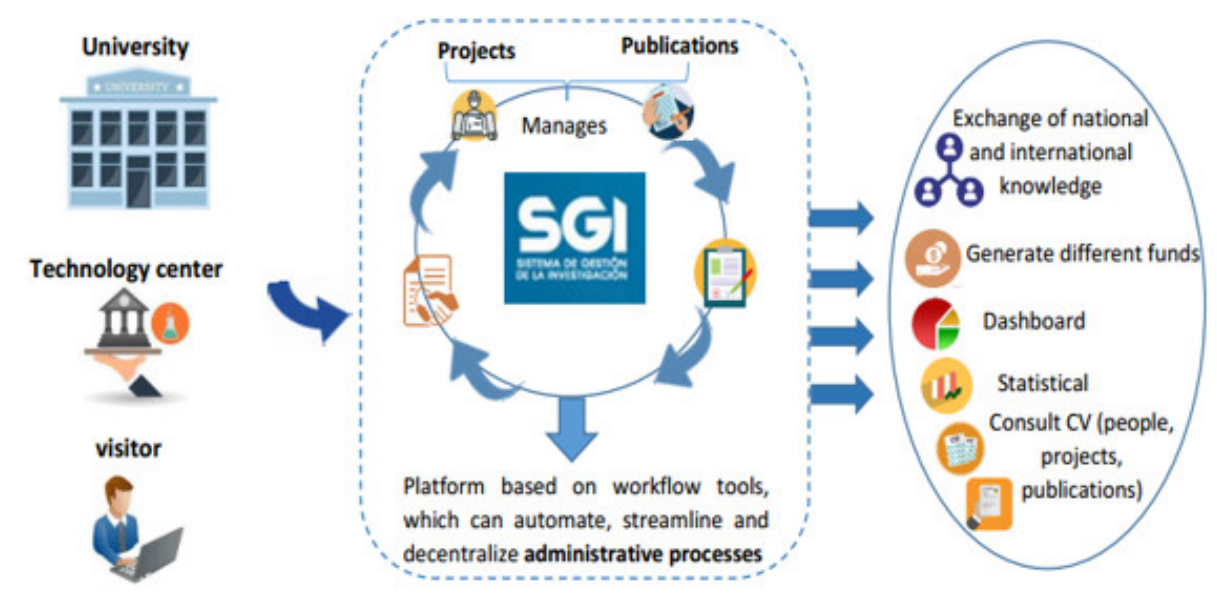

Figure 1: The functional perimeter of SGI

\section{Information System of Science and Technology (SICyTAR), Argentina}

The Ministry of Science, Technology and Productive Innovation of Argentina has set up the Science and Technology Information System (SICYTAR) to facilitate and unify access to information on Scientists, technicians and their jobs. SICYTARwas created in 2002. Meanwhile, the strategic importance of SICYTARis to keep a unified register constantly updated; produce detailed statistical information to develop 
Khaoula Benmoussa, Majida Laaziri, Samira Khoulji and Kerkeb Mohamed Larbi, Comparative Study of Governance Information Systems for Scientific Research. Transactions on Machine Learning and Artificial Intelligence, Vol 5 No 4 August (2017); p: 768-775

indicators and to evaluate science and technology policies; provide a useful tool for networking among researchers as well as with government and business sectors.

With this important inter-agency support, the Ministry has faced the development of CV registry according to the agreed design: CVar. The CVar is a central application loaded with school data, the result of joint work between the Ministry and the National Council for Scientific and Technical Research, and it is part of SICYTAR.

This new platform also includes an InfoSICYTAR service, with general consultation statistics that presents two platforms (GEICYT, SICYTARBox) for exclusive use by SNCTI institutions.

Among the new features integrated in SICYTAR is BuscaCV.ar : A thematic research system of people that promotes the exchange of information between individuals, groups and institutions. This tool allows accessingasummarized curriculum vitae data of each teacher and researcher [4].

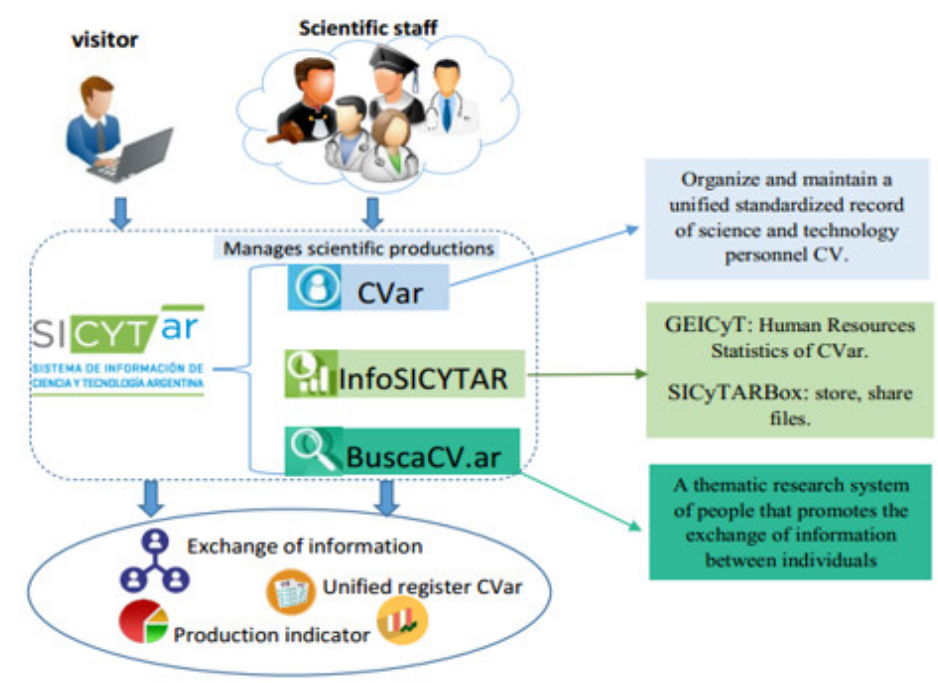

Figure 2: The functional perimeter of SICYTar

\section{Scientific Information System of Andalusia (SICA), Spain}

S.I.C.A was born as a research project in July 2001. Thanks to a cooperation agreement between the Ministry of Education and Culture of the Government of Andalusia and the University of Granada in order to meet the specific needs of the operational management organisms to promote research and technological development in Spain.

the Scientific Information System of Andalusia, SICA, can be defined as a set of people, processes and equipment designed, constructed, operated and maintained to collect, record, process, store, retrieve and display information related to activities and results produced by researchers in their development centers or in collaboration with other national or international institutions

All these factors have databases that store information to producers and agents (researchers, scientific institutions, research groups, $R \& D$, etc.) on the one hand, and the results of their research activity (Transfer of scientific production technology, curriculum teaching and research, etc.)on the other hand. These databases are usually ad-hoc systems or bibliographic data[5-6]. 


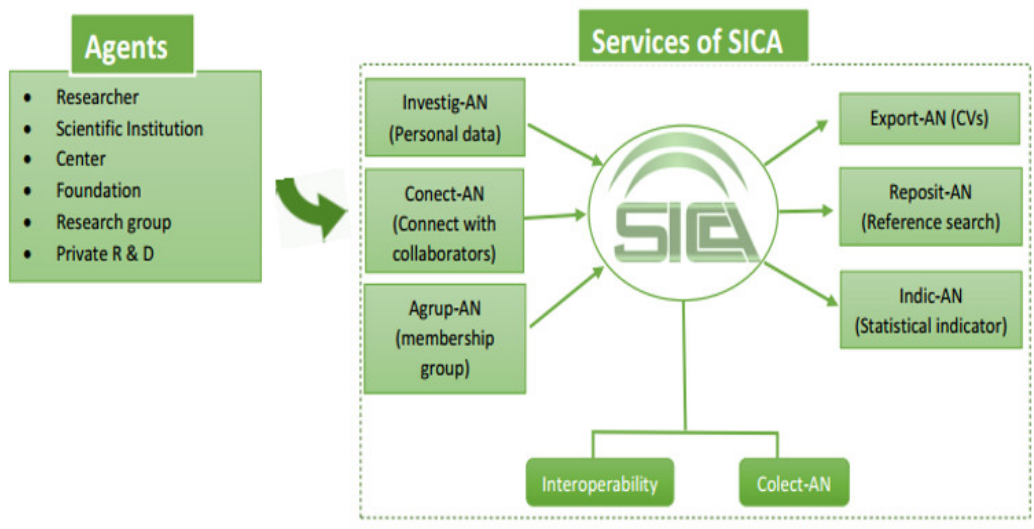

Figure 3: The functional perimeter of SICA

\section{Management of Research Data, Application of Laboratory Activities (GRAAL), France}

GRAAL (Management of Research Data, Application of Laboratory Activities) is a software program launched in 2000 by the Inter-University Center of Computing in Grenoble. Its piloting was entrusted to a Group of scientific interest (GIS) gathering interested public partners. At the end of 2009, GRAAL was deployed in some fifty establishments.

GRAAL is an application that aimed to present the research units within the universityin a coherent way, including the personnel and their scientific activities (publications, patents, eventsand equipments) as well as the monitoring of financial resources (Endowments Quadrennial contracts and tenders) and international activities (Conventions of partnership, congresses). It allows the data to be historicized and thus to monitor and manage the transformations of research units, financial and human resources, and indicators. It allows three levels of hierarchy in the institution to enter or access certain data: the research unit, The Research Directorate and the presidency.

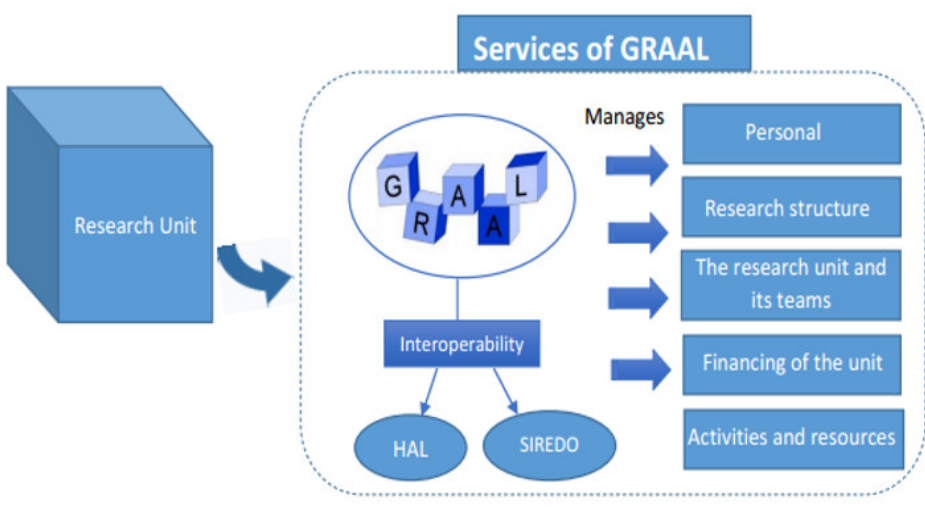

Figure 4: The functional perimeter of GRAAL

\section{Moroccan information system for scientific research (SIMArech)}

The Moroccan Ministry of Higher Education and Scientific Research has shown great interest in the development of an Information System for Scientific Research. SIMArech was created at Abdelmalek Essaâdi University in 2008 in order to contribute to enhancing the potential of research by highlighting 
scientific production and Know-how of researchers. SIMArechcould be also used as an instrument of evaluation and could help making decisions.

SIMarech provides a description of the existing situation and a study of the needs for a better optimization of human and material resources. It also allows in a national context of evaluation of the research to engage in a quantitative assessment process that would provide objective criteria for self-assessment and external peer review.It is configurable and allows a transcendent role assignment: teacher-researcher, responsible for the research unit, high education institution and university administrator. Its reporting system makes it possible to print documents, graphs and statistics on various sections specific to research: indexed publications, communications, projects, patents, etc. [10].
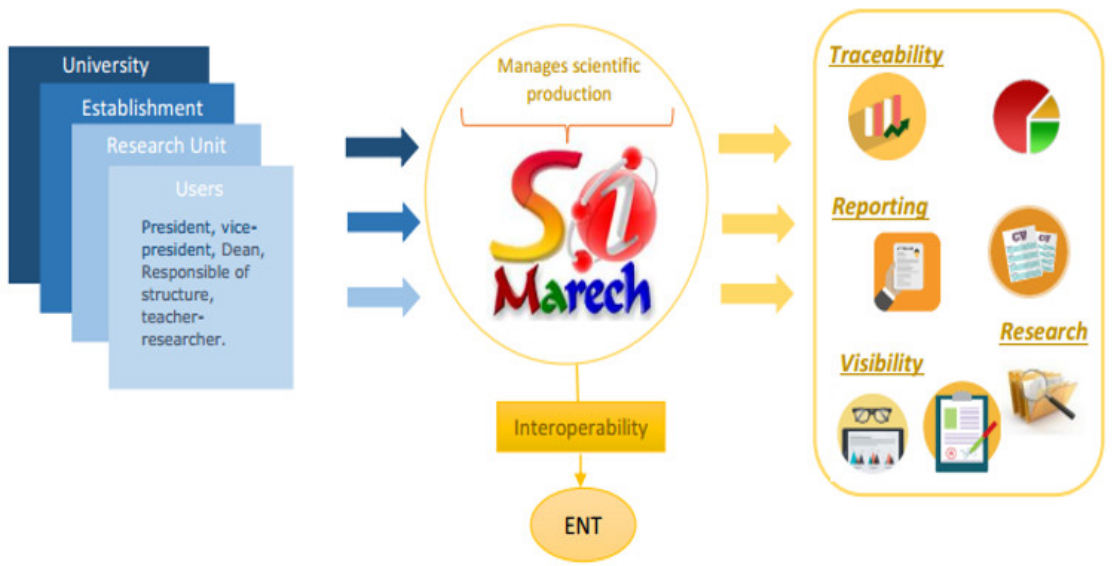

Figure 5: The functional perimeter of SIMArech

\section{IRIS (Institutional Research Information System) Italy}

IRIS (Institutional Research Information System) is an IT platform for the management of data on research activities (people, projects, publications) adopted by the University of L'Aquila, Italy in 2015. IRIS aims at collecting, managing and storing data related to the University's scientific research output. Professors, researchers, research fellows and Ph.D. students, together with administrative staff members can access the platform using their login credentials in order to catalogue their published research works. IRIS also aims at monitoring research results and enhancing visibility of the University's output. IRIS has five different modules integrated together through standard protocols and interfaces. One of the main components of IRIS is DSpace-CRIS, an open source solution that can also be used as a standalone system, and as such is now installed in seven institutions outside Italy [7].

The system complies with the high standards of representation of scientific entities (people, equipment, installations, projects, etc.) recognized internationally by facilitating access to international scientific networks for Italian universities. The application also allows managing the internal search establishment processes and collect useful data to fulfill several ministerial or European Unionrequirements.

The new system is a valuable aid:

- For government agencies that will monitor the progress of activities, outputs (e.g. products and publications) achievements, and a plan for investment of new funds; 
- For researchers and relevant offices, they can obtain an overview of the results of existing research projects, CVs of researchers, bibliographies, and tools available; thus, promoting contacts and collaborations between researchers and the reality of companies.

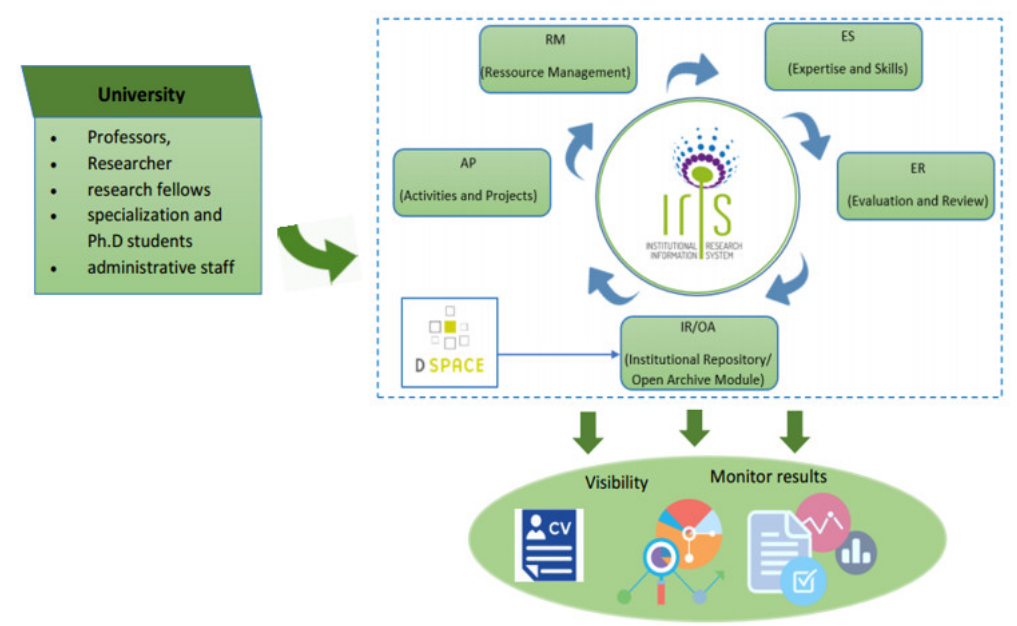

Figure 6: The functional perimeter of IRIS

\section{Infocentre research (Infocentrerecherche), France}

In 2004 the university paulcézanne Aix-Marseille III launched a project called Infocentre research.The latter is an information system and tool to aid the piloting of the research of an establishment based on the use of a CMS (Content Management System) of the collaborative extranet type and it is totally configurable "in real time". Its flexibility makes it able to adapt dynamically to the specificities of the institution or research unit considered. Thus, this InfocentreResearch is an instrument capable of continuously drawing up a "state of the art" or "dashboard" for these structures.

Emphasis is placed on the fact that local research structures, as well as national structures, have less need of evaluation than of valorization of research. It allows research structures to collect structure data in international databases, add additional metadata, data validation by the relevant actors, the setting up of various reading grids, the composition of dashboards, Etc.

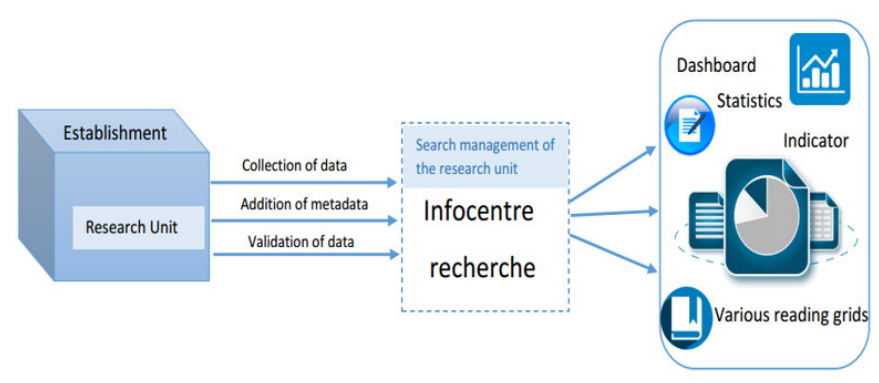

Figure 7: The functional perimeter of infocentrerecherche

\section{Integrated Management and Evaluation System SIGEVA, Argentina}

Integrated management system and Evaluation- SIGEVA- is a set of computer applications that can be accessed safely through a web platform (intranet) and via an Internet browser. The system was created 
Khaoula Benmoussa, Majida Laaziri, Samira Khoulji and Kerkeb Mohamed Larbi, Comparative Study of Governance Information Systems for Scientific Research. Transactions on Machine Learning and Artificial Intelligence, Vol 5 No 4 August (2017); p: 768-775

in 2005, developed by the department of computer systems organization and CONICET management to generate information, standardize processes, manage and evaluate individuals and research groups, and systematizing information.

This system manages processes, both administrative and academic. It is composed of different modules, module of management of the calls (Management and control, evaluation, decision), Compile module (avoids the duplication of the records), interoperability module, activities module (100\% CVarcompatible), Personal Data, Training, Scientific Production, Production Technology, Funds, handles ROLES allowing different users to access certain information and functionality throughout the process[8-9].

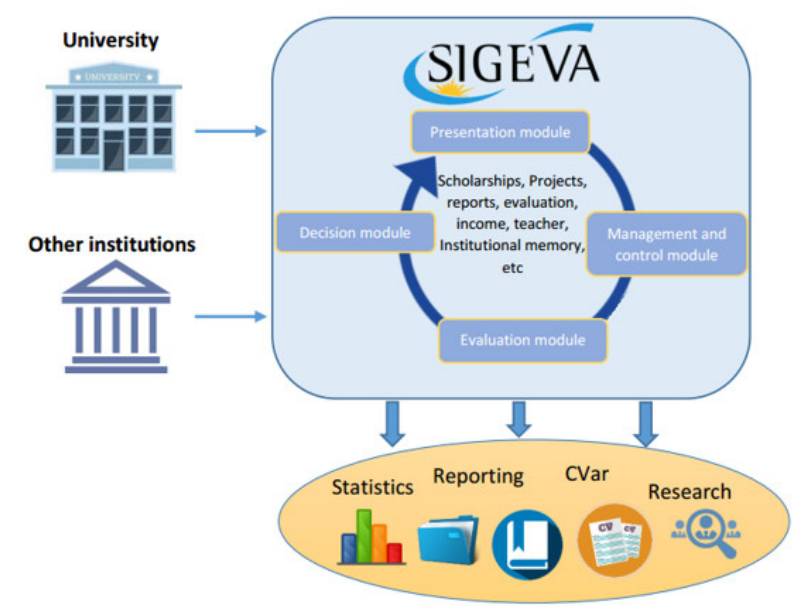

Figure 8: The functional perimeter of SIGEVA

\section{Conclusion}

In all developed countries, scientific and technological development has become particularly important. Meanwhile, to meet the challenge of being effective in managing research at universities, the amount spent on research and the expectations they deliver to Quality are enormous. Rather than leaving research management, evaluation, impact and reputation to random execution, the institution is better servedwith a research management solution through an information system that responds to the requirements of a high level of operational, tactical and strategic institutional authorities, its researchers, the various stakeholders in research and its results, including business and government.

In fact, the study found that many countries are struggling with similar governance issues. A critical one is how to arrive to a coherent management of science, technology and innovation policy. The study identified that in spite of an existing global research, the need for greater coherence and integration of how are research performers (universities and public research organizations) held accountable for their activities, and how do national and regional actors coordinate their activities.

We have identified various responses to the above questions in the benchmark countries. In all governance systems, there are linear modes of operation function in parallel with more systemic and integrative modes of operation.Partly this can be explained by path dependency and a long cultural heritage, to some extent since some elements of the linear model still fulfill a function in a systemic governance model.

Figure 8: The functional perimeter of SIGEVA 
Countries are converging on the idea that there should be a very high-level research policy function to generate a high quantitative and qualitative scientific production.Concerning the synergy between national and regional research activities, we found that in most studied countries, the co-ordination does not exist.

Overall, the governance models in the benchmark countries can be seen as a continuous learning process of adopting organizations and practices to external and internal challenges. The snapshot view that has been provided by this study cannot capture this national specific historical process in great depth. Similarly, good practices cannot simply be transferred from one country to another. Nevertheless, the illustrations how the benchmark countries have tackled some of the key research governance issues, provide food for thought to improve the efficiency of any new research information system.

\section{REFERENCES}

[1] R.Claudia, N.José, S.Samaly, S.Cabrera Francisco, Fernández Juan Antonio, Chaichio Juan Antonio, 'Sistema de Información Científica de Andalucía: una herramienta para la evaluación y gestión de los resultados de la actividad científica',31 may.2006. https://core.ac.uk/download/pdf/11880141.pdf

[2] I.manderieux, 'guía práctica para la creación y la gestiónde oficinas de transferencia de tecnología en universidades y centros de investigación de américa latina', June 2011.

[3] F. Palomo, Carlos G. Veloso, y Rodolfo F. Schmal, 'Sistema de Gestión de la Investigación en la Universidad de Talca, Chile', InformationTechnology ,Vol. 18 N1 - 2007, pp. 97-106.

[4] J. Ferrer, C. Clemenza, 'Gestión de la investigación universitaria: Un paradigma no concluido', Multiciencias, vol. 6, num. 2, mayAugust, 2006, pp. 188-193.

[5] F.Manuel Solís Cabrera, 'El sistema de información científica de Andalucía, una experiencia pionera en España',2006.

[6] Scientific Information System of Andalusia (SICA) [online] Available:https://sica2.cica.es

[7] A.Bollini, M.Mennielli, S.Mornati, DT.Palmer,' IRIS: Supporting \& Managing the Research Life-cycle', Universal Journal of Educational Research, vol. 4 n. 4, 2016, p. $738-743$.

[8] Integrated Management and Evaluation System (SIGEVA) [online] Available: http://sigeva.conicet.gov.ar

[9] [9] Management System for Research (SGI) [online] Available: http://sgi.utalca.cl/directorio_new.php

[10] Moroccan Information System for Scientific Research (SIMArech) [online] Available:http://www.sirech.uae.ma/portail/public/index.php 